\title{
ENTREVISTA COM RUTH CARDOSO
}

\author{
Por Ana Cristina Braga Martes e Mario Aquino Alves
}

0 debate acadêmico sobre movimentos sociais e participação popular carece de trabalhos que possam ajudar a compreender, sob uma perspectiva histórica e política, as atuais formas de organização social, especialmente as ONGs e demais organizações do terceiro setor. Há mais de uma década, os pesquisadores tendem a interpretar a promulgação da Constituição de 1988 como o ponto de partida das recentes práticas de democracia participativa, com destaque para os estudos sobre orçamento participativo e planejamento municipal. Desconsiderase que essas mesmas práticas têm origem em práticas anteriores, como, por exemplo, nas experiências, na década de 1980, sobretudo no estado de São Paulo, da discussão de políticas públicas e de formas de gestão a partir de consel hos, com a participação de representantes dos movimentos sociais.

Ruth Cardoso foi, durante os anos 1980, uma das pesquisadoras brasileiras que melhor observou esse fenômeno no período de transição democrática, marcado pela atuação dos movimentos sociais de contestação popular nas periferias urbanas e, ao mesmo tempo, pela abertura do diálogo com os movimentos de reivindicação, por parte de alguns governos.
Listado no final desta entrevista encontra-se o essencial, acreditamos, desse material de pesquisas realizadas por Ruth Cardoso no Centro Brasileiro de Análise e Planejamento (Cebrap), nos anos 1980. Nossa expectativa é de que este debate possa trazer de volta importantes questões institucionais em torno da participação popular e novas formas de representação, no âmbito de uma "discussão perdida": Estado-sociedade fruto de um contexto político de redemocratização.

Nos anos 1980 a senhora montou uma equipe no Centro Brasileiro de Análise e Planejamento (C ebrap) para estudar movimentos sociais, acompanhar o processo de descentralização do Estado e as iniciativas inovadoras de promoção da participação popular nas agências públicas. Atualmente as publicações sobre participação popular apontam a Constituição de 1988 como sendo o marco de tais iniciativas. Esqueceram a década de 1980?

RC: Tudo indica que sim. Recentemente, em uma palestra argumentei: "Se pretendemos falar de participação, vamos considerar que existe um passado, geral mente esqueci- do até por razões ideológicas e políticas, pois se trata de um processo construído em algumas décadas". Acredito que desde os anos 1970 viemos construindo uma sociedade participativa. Esse era um dos principais pressupostos do Programa Comunidade Solidária: ${ }^{1}$ tínhamos uma sociedade mobilizada, composta por uma rede de organizações, de níveis muito diferentes, de eficácias muito diferentes. No entanto, as resistências que encontrei, em 1995, não vieram da oposição, mas da imprensa, pois ela era cética em relação a este pressuposto. Para mim, contudo, era bastante claro: a sociedade brasileira era mobilizada, e portanto a gente tinha que fortalecer, trabal har a parceria governo-sociedade civil. A imprensa não acreditava, por exemplo, que os empresários estariam dispostos a ter uma participação, a ajudar, a fazer parcerias. Era sempre aquela idéia: “Empresários brasileiros, imagina! N unca participam de nada, não querem...". 0 que não percebiam era a ocorrência de uma importante mudança.

Nas décadas de 1970 e 1980, deuse o desenvolvimento de inúmeras redes sociais, ligadas aos movimentos sociais, especial mente de reivindicações urbanas e da mobilização 
de bai rros populares. Tais redes ajudaram a formar o contexto da oposição ao regime militar. Cresceram, em parte, a partir do trabalho de base da I greja Católica, mas também de movimentos sociais do tipo: movimento negro, de mulheres e movimento gay. Nos anos 1970, sem dúvida, eles se formaram. Na década seguinte, tal como procurei analisar em um artigo do livro organizado por Lourdes Sola e Leda Paulani (1995) sobre a década perdida, tais redes se expandiram consideravel mente. N esse artigo eu defendia a idéia de que a década de 1980 pode até ter sido uma década perdida do ponto de vista econômico, mas do ponto de vista da sociedade, ela foi uma década riquíssima. Deu-se início ao processo de democratização dos governos estaduais. ${ }^{2}$ Então começa a ser construído um diálogo institucional diferente entre sociedade e Estado, até então predominantemente caracterizado pela contestação. N esse momento, com o começo da democratização, criamse os consel hos que depois começávamos a estudar no Cebrap. Naquela época os consel hos representavam o máximo da reivindicação participativa que até então podíamos imaginar.

Os conselhos traziam, na época, a possibilidade de dar à participação popular uma forma estável. A preocupação que se tinha na época era com a instabilidade dos movimentos: as reivindicações apareciam e, assim que atendidas, a mobilização terminada, os grupos se dispersavam. Então o conselho possibilitava a permanência.

RC: De fato, assim pensávamos, porque depois também os conselhos se burocratizaram. Mas acho que houve uma mudança na relação dessas organizações da sociedade civil com o poder público, nos lugares onde a democratização foi um pouco mais profunda. Por isso esse processo é muito desigual no país inteiro. Começou-se um diálogo que é sempre difícil, porque uma coisa que foi criada para ser contestatória traz um grau maior de dificuldade na relação com seus interlocutores. Todas as pesquisas que fizemos naquela época eram exatamente para mostrar como era difícil fazer funcionar um consel ho. Por quê? Porque também o movimento social atua no sentido de criar uma relação nova, e essa relação nova não passa pela representação. Esse é um problema que acho que é absolutamente fundamental. Não está resolvido, também não sei como resolver, mas temos que nos debruçar sobre ele. As reivindicações dirigemse para, e assumem uma forma de contestação ao governo, ao Executivo. Para o governo, por sua vez, essa relação que se quer direta é difícil, porque ele tem que atender à totalidade de reivindicações, e não apenas a segmentos específicos. 0 clima nos anos 1980 era o de se forçar uma relação institucional diferente. $\mathrm{Na}$ verdade, os grupos que pressionavam se sentiam representantes e tinham al gum respaldo. Mas não há o mecanismo de representação e esse mecanismo é negado por essa rel ação, que é construída como uma relação direta. A cho que isso é uma coisa muito importante; não aconteceu nos anos 1980, com a redemocratização. $\mathrm{Na}$ verdade, começou antes.

A dificuldade dos diversos conselhos (Habitação, Saúde, etc.) estava, exatamente, em que esse tipo de representação se choca com o sistema de partidos, com o sistema de representação tradicional, de pressões. A Constituinte 3 apareceu como o coroamento desse momento de grande participação. Mas aí, também curiosamente, como se abriram as portas da Constituinte, a pressão recaiu sobre o Legislativo. Então foi para as emendas, para as leis, etc. N aquele momento, houve certa convergência entre o sistema representativo e esse sistema informal de pressão. Entre outras coisas, essa combinação foi possível por causa do clima naquel e momento, que era de abertura. Na década de 1990, a sociedade deu início a um diálogo institucional, houve aprendizado e criação de novos canais. E foi isso que se esqueceu completamente.

\section{E a década de 1990 ?}

RC: Acho que se dá uma mudança no interior da sociedade. Por exemplo, as empresas mudam. Mudou a mentalidade dos empresários, mudou a maneira deles se relacionarem com a sociedade, aparece a idéia da responsabilidade social das empresas, que ajuda a criar um espaço novo: o terceiro setor. Da minha experiência no Comunidade Solidária, percebo que grande parte deles acredita conhecer e entender a área social, que sabem identificar os problemas sociais, bem como resolvêlos. A verdade é que eles estão muito mais engajados. Hoje um empresário não dá dinheiro para alguém fazer al guma coisa filantropicamente, para "salvar os vel hinhos". Eles realmente querem saber como, por quê, quanto custa, onde vai ser, por que é assim, por que é assado. A doação do dinheiro é condicionada à aprovação do projeto.

\section{E onde entra o marketing?}

RC: Sem dúvida, eles têm uma visão marqueteira também, que, aliás, acho normal e sou a favor. Ótimo será o dia em que alguém comprar um produto porque reconhece naquela marca algum tipo de investi- 
mento social; será melhor do que a situação que se tem hoje. Agora, o que é ruim é quando o critério é definido meramente pelo marketing. Já quando os empresários escolhem projetos, demonstram ter idéias muito enraizadas a respeito. Por exemplo, quando comecei a trabaIhar com os jovens no Comunidade Solidária, essa era uma questão que se colocava fora da visibilidade do empresariado. Jovens não eram vistos como um problema. Tivemos que convencê-los, e os programas deram certo. Já os programas de alfabetização de jovens e adultos: isso é um problema aceito, conhecido. Então, em 1996, para eu fazer o programa de capacitação de jovens, ${ }^{4}$ que era estratégico naquel e momento, tive que dedicar horas de convencimento a todos os meus parceiros, justificando por que focalizar nos jovens e não trabalhar apenas com meninos de rua. Porque naquele momento as notícias enfatizavam a existência de 3 milhões de meninos de rua, toda a visibilidade estava em cima dessa questão. E, na verdade, em parte consegui apoio para o programa de Capacitação de Jovens porque eu dizia: "Olha, este programa evita que o menino vá para a rua; antes, ele protege 0 adolescente".

Para resumir, vol tando à pergunta, acho que nos anos 1990 tivemos uma congeminação de coisas. Em primeiro lugar, o processo de democratização. Tínhamos uma sociedade mobilizada e pronta para oferecer serviços, porque tudo aquilo que era movimento, acabou gerando ONGs, explicando de uma maneira simplificada... Mas, enfim, de cada um desses movimentos surgiram ON Gs que tratavam de dar uma assistência, de fazer al guma coisa, de resolver algum problema concreto. Isso tanto nos movimentos populares quanto nos movimentos feminis- tas, movimento negro e outros. Isso antes era muito desvalorizado, porque todo pensamento de esquerda era contra, eram ações que, como se acreditava, deveriam ser feitas pelo Estado e não pela sociedade. Nos anos 1980, os mutirões de guias e sarjetas, do Mário Covas, eram vistos pelas lideranças de alguns movimentos como exploração. Isso foi um nó que no começo dos anos 1990 se desfez, pelo menos em parte. 0 terceiro setor se desenvolveu exatamente porque tinha essas duas condições: os empresários mudando a sua mentalidade e uma sociedade mobilizada, tentando fazer coisas. Por que eu valorizo essa participação da sociedade? Porque acho que nesse tentar fazer coisas a sociedade civil trouxe experiências riquíssimas e inovadoras. É evidente que a sociedade é capaz de inovar muito mais que o Estado.

\section{Gostaria que explicasse 0 proces- so das rodadas de interlocução po- lítica do Comunidade Solidária e seus resultados.}

RC: Isso é resultado do processo que eu estava descrevendo. Acho que nos anos 1990 você tem, por um lado, uma sociedade que já está mobilizada e que já tem para oferecer experiências inovadoras em educação, saúde, movimentos de muIheres. Muitas escolas com nova pedagogia, os mutirões com novas maneiras de construir, são coisas experimentais e criativas, respostas diferentes para a tradicional resposta universal que vem do Estado, pois o Estado tem que estender seu atendimento a todos.

Naquele momento, era claro para nós que o mundo inteiro tinha mudado e que nós também tínhamos que mudar, tínhamos que desenvolver esse diálogo. Tentar abrir canais de comunicação entre Estado e essa gen- te, o que era dificílimo. Porque cada um tem a sua história, e aqueles que tinham realizado experiências novas, tinham horror ao Estado, horror ao governo. E, por sua vez, havia a resistência da burocracia estatal. Falávamos em parceria e víamos o que era a resistência. Parceria não existe para a burocracia estatal. Do lado do governo há também desconfiança com relação ao que eles (ONGs) querem fazer, e da demanda pela independência e ausência de controle. Então o diálogo é complicado.

As Interlocuções Políticas foram inventadas para possibilitar esse diálogo, e nisso tivemos muito sucesso, porque trabalhamos com temas bem complicados e conseguimos colocar frente a frente representantes do governo e da sociedade civil. Evidentemente não se chega a muito, nem se fazem grandes progressos, porque são atitudes muito enraizadas. Mas conseguimos, por exemplo, chegar a um acordo para que as terras entregues ao Banco do Brasil por dívida fossem para a reforma agrária, algo que era uma reivindicação do M ST. Conseguimos a reformulação de alguns processos do próprio Ministério da Reforma Agrária com relação ao reconhecimento de terras. Foram pequenas mudanças, mas considero que foi um sucesso sentar todo mundo junto pela primeira vez.

Nesse período (1995-1999), por meio das rodadas de interlocução política, abre-se a discussão em torno da reforma do Marco Legal, ${ }^{5}$ o reconhecimento organizacional dessas novas formações da sociedade civil. C omo você analisa esse ponto, especificamente?

RC: Acho que tivemos resultados cujas conseqüências são mais importantes, como a Lei das OSCIPs. A Lei do Voluntariado é uma coisa 
que ficou. Chamamos todo mundo, e, interessante, havia mais consenso entre a sociedade civil do que na burocracia.

Houve uma resistência muito forte por parte da burocracia, principalmente no entendimento da Lei das OSCIPs (O rganizações da Sociedade Civil de Interesse Público). Por exemplo, o Conselho Estadual da Assistência Social, aqui em São Paulo, teve problemas em reconhecer os títulos: se uma organização virou OSCIP, então não podia ser considerada de utilidade pública. É realmente uma coisa bastante interessante, dentro desse processo, essa resistência por parte da burocracia do Estado em não reconhecer alguma coisa que, na verdade, emana de lei.

RC: Sempre há, também, resistência do lado das ONGs, daquelas organizações tradicionais, de assistentes sociais que não gostavam muito dessas mudanças... Tivemos interlocuções cujo resultado pal pável, no fim, não foi tão grande, mas 0 fato de termos estabel ecido o diálogo foi fundamental. E outras, onde o diálogo foi muito mais fácil e 0 resultado positivo, como a Lei do Voluntariado; enfim, mudanças que foram significativas, mas até hoje difíceis de implementar.

Se nos anos 1990 as ONG s começaram a ser vistas como uma grande alternativa, mais recentemente, para autores como James Petras, ${ }^{6}$ por exemplo, elas passaram a ser vistas com certo distanciamento. Alguns chegam mesmo a falar que elas não mais estão no campo progressista, que são agora a face comunitária do neoliberalismo. 0 que você acha?

RC: 0 processo que veio dos anos 1970 foi todo recortado por ideolo- gias. Já me referi à esquerda que tinha uma visão estadista, e que na verdade teve que obrigatoriamente rever sua posição em relação ao papel e função do Estado. Mas ainda há setores da esquerda com essa visão puramente estadista e que, portanto, não reconhecem o papel da sociedade civil. Reconhecem elegitimam apenas - e acho que é o caso dessa distinção que você mencionou os setores sociais que são coerentes em relação à visão de transformação do mundo que eles têm.

Dentro de uma visão estreita sobre Gramsci e sua obra, ${ }^{7}$ de um certo gramscianismo que pode ser assim resumido: a sociedade civil é um meio para atingir a sociedade política, mas aí um partido, uma classe social, tem um projeto, e, na medida em que esse projeto se implementa, para que sociedade civil?

RC: Não, acho que o Gramsci era mais sofisticado. Eles fizeram uma simplificação. Porque Gramsci trabalha com o conceito de hegemonia, que dá a essa questão uma outra dimensão. Claro que Gramsci é um homem de partido. M as ele vê 0 partido como instrumento da transformação, porém a transformação se faz por meio da hegemonia do partido. A construção da hegemonia é social pela construção de valores consensuais. Portanto, você muda os valores do partido, se for o caso, para construir essa hegemonia. Isso os partidos de esquerda esqueceram. Quando você trabal ha com uma dicotomia como esta - "os progressistas e os neoliberais comunitários" -, que critério você está utilizando? Tal critério não pode ser gramsciano porque não se trabalha com 0 conceito de hegemonia. Se fosse, caberia a pergunta: como trazer neoliberais para o progressismo? Esse critério usado para separar uns de outros é de quem? De quem está olhando por que um é progressista e outro não.

Esse tipo de abordagem é muito semel hante a uma certa literatura que tínhamos nos anos 1980 e que também trabalhava com a seguinte divisão: de um lado, as Sociedades Amigos de Bairros (SABs), organizações cooptadas pelo Estado; e de outro, os movimentos de esquerda (chamados autênticos), que iriam ajudar a revolução.

RC: No movimento feminista também se dividia. Algumas teses eram ótimas, outras já não eram tão boas, porque não eram necessariamente coerentes com a idéia de mudança social, revolução, etc. Eram divisores de águas, embora sem a utilização da palavra neoliberal.

0 pressuposto aqui também é de que as ONGs, como os movimentos sociais para alguns naquela época, teriam um papel especial, progressista e até revolucionário a cumprir.

RC: Estou total mente de acordo. Os movimentos sociais deram origem a muitas das ONGs. Eles passaram a prestar alguns serviços e a institucionalizar esses serviços. Começou-se a ter um caminho diferente: maior diálogo com o Estado, maior diálogo institucional. Tanto em reIação às ONGs quanto aos movimentos sociais, tem que se ter como pressuposto que a sociedade civil é por definição heterogênea. Por exemplo, não aceito essa distinção entre neoliberal e progressista, porque não acho que caiba a movimentos ou organizações que vêm da sociedade civil. Essas organizações vão expressar exatamente aquilo que há de contraditório. Por isso é que fazíamos, no Comunidade Solidária, 
as nossas reuniões chamando 0 Stédile e o representante dos proprietários rurais. A mbos são sociedade civil. Agora, quando você começa a trabalhar com esse critério ideológico, você diz: "Não! O Stédile é bom, o outro é reacionário, ruim, neoliberal, etc.", e não reconhece a heterogeneidade das organizações, que é a base da democracia. Então, você tem que estar convencido da democracia como principal valor, para poder trabalhar com a sociedade nesses termos.

\section{U ma coisa que gosto muito do tra- balho que fizemos no Cebrap ${ }^{8}$ foi termos chamado a atenção e pes- quisado esse processo de institu- cionalização. Fomos atrás, acom- panhamos, buscamos explicar aquelas novas formas de organiza- ção e participação popular. Isso aconteceu num período em que to- dos, na academia, apostavam no caráter revolucionário dos movi- mentos populares urbanos.}

RC: E nós falávamos total mente sozinhas naquela época porque exatamente a visão dominante era essa, dos "progressistas". Essa visão não se coaduna com uma visão estadista. E aquela, a visão dominante na época, que todos nós também até respeitávamos, era uma visão ainda de esquerda, inclusive do PT. Depois, nos anos 1990, foi impossível exercer controle ideológico sobre essas questões, porque as mu danças foram grandes, não apenas no Brasil, mas no mundo. Nos anos 1990, a expansão do terceiro setor se deu em todos os lugares. E aqui também. Então, conseqü entemente, essa relação dos governos com as organizações sociais foi se expandindo. Tornou-se óbvio que o Estado precisa dessas organizações para organizar uma série de trabalhos, de coisas que o Estado não pode fazer, porque a sociedade se segmentou muito, de modo que suas demandas tornaram-se também muito segmentadas. Qualquer governo terá que lidar com meninos de rua, por exemplo, ou com idosos. É óbvio que, por existirem organizações civis que trabal ham com essas populações - numa escala menor -, a qualidade do trabalho tende a ser melhor. 0 Estado, por sua vez, não tem como responder a isso, porque são problemas fragmentados, e eu sempre digo: "O Estado tem que se dedicar a atender aos direitos universais. Escola para todo mundo? É o Estado que tem que dar...". Agora, a pós-escola para os meninos deficientes é outro problema. É aí que a sociedade tem tido mesmo uma contribuição reconhecida.

Em minha opinião, as pessoas demonstram certo cinismo ou descrença em relação à responsabilidade social das empresas. Em sua opinião, o que há por trás, se é que há algo, das doações dos empresários?

RC: Vejo de outro modo. Hoje em dia, a própria maneira de gerir uma empresa e criar sua imagem recebe outro tratamento. Os empresários estão muito mais atentos, acreditam precisar ter uma participação que vai muito além dos interesses econômicos imediatos. Querem gan har dinheiro, continuam ganhando dinheiro, evidentemente. $M$ as aquela antiga racional idade hoje é mais sofisticada porque implica também que uma empresa construa a sua imagem. Ela depende dessa imagem, o mercado exige isso. $N$ ão porque 0 empresário seja ou tenha se tornado "bonzinho", mas porque, de outro modo, ele pode sofrer também muitos atropelos. Temos o caso da Nike, acusada de empregar trabal ho escravo. Isso não existia antes! U sar trabalho escravo era um modo encarado como racional para se ganhar mais dinheiro. Então acho que a mentalidade dos empresários mudou. E hoje faz parte da racionalidade econômica ter al guma visão da sociedade e do papel da sua empresa na sociedade. Agora eles participam, querem acompanhar resultados, interferir nas ONGs, no terceiro setor. Em al guns casos, a contribuição chega a ser bastante positiva, no sentido de que demanda meIhor gerenciamento.

Hoje você muito dificilmente tem apoio de uma empresa se não tiver avaliação de trabal ho. Porque é uma coisa da cabeça dos empresários. As ONGs foram muito influenciadas pela forma de gestão das empresas, e as que não conseguirem um bom gerenciamento vão perecer. Essa é a substituição da antiga filantropia das senhoras católicas pelas ON Gs. Tudo isso continua a existir. Muitas se modernizando, mesmo as que nasceram como organizações filantrópicas do tipo antigo. Começam a perceber que não dá mais para trabal har. $N$ ão é porque estou fazendo o bem que alguém vem aqui e vai me dar dinheiro. Está muito difícil, o mercado é muito competitivo, o terceiro setor cresceu muito. Essa profissionalização das ONGs é o processo normal em curso. Sempre haverá um asilo aqui, uma senhora ali, isso sempre haverá, no velho estilo filantrópico. Mas, acho, esse estilo sofreu uma mudança, e essa mudança foi muito marcada pelo empresariado. Ninguém perguntava quanto custava a filantropia, ninguém perguntava se poderia ser mais racional a gestão. Não existia essa idéia, a idéia era atender. Hoje não é assim. N em o Estado nem o mercado colocam dinheiro num programa ou organização sem saber quanto custa, se pode rebaixar esse custo, se pode gerenciar 
melhor o dinheiro. E acho que isso está tendo uma enorme influência sobre as ONGs.

\section{É reduzir demais a ação do empre- sário, pensar que é apenas aquela racionalidade econômica. $\mathrm{Na}$ ver- dade, há mais uma busca pela legi- timidade de fato do que um retor- no econômico. Os empresários têm que ser eficientes e ao mesmo tem- po legítimos, dentro de um deter- minado espaço. Agora, o que eu queria perguntar é o seguinte: a visão do empresário, hoje, atuan- do nesse setor, ele consegue ter uma visão universal dos problemas ou ainda tem uma visão particula- rizada sobre essas questões? \\ RC : Esse é o grande problema. Por- que acho que houve toda essa mu- dança de mentalidade, e acho que realmente eles não ficaram melho- res como pessoas, não. A racionali- dade e a eficiência para el es ganha- rem dinheiro é que os levam a ter esse tipo de conduta, porque você \\ BIOGRAFIA E OBRA \\ Ruth Correa Leite Cardoso nasceu em Araraquara (SP), em 1930. Pro- fessora aposentada pela Universida- de de São Paulo, é atualmente pre- sidente da Comunitas, organização não governamental promotora de parcerias entre sociedade civil, uni- versidades e empresas, com o ob- jetivo de otimizar os recursos em- pregados no combate à pobreza e à exclusão social. Foi também presi- dente do Comunidade Solidária. Antropóloga, a dra. Ruth Cardoso tem ensinado, pesquisado e escrito sobre temas das áreas de Cultura e Política: movimentos sociais, par- ticipação política, imigração, ju- ventude, comunicação de massa, violência e cidadania.} não pode esquecer que o conceito de responsabilidade social não é apenas apoiar políticas sociais de O N Gs, etc. A primeira coisa relacionada a esse conceito é tratar bem 0 funcionário. U ma ação voltada para dentro e não para fora. Esse foi 0 que se desenvolveu mais facilmente, porque é muito visível. $E$ tudo isso por quê? Por uma medida de eficácia. Na mentalidade empresarial moderna, assumir esses encargos (vamos chamar assim), os de dentro e os da comunidade, são mecanismos que tornam mais eficaz a conquista de seu objetivo. Não é porque el es viraram santos. Mas, de qualquer forma, é um processo positivo. Por quê? Porque é um processo democrático que engloba 0 setor produtivo da sociedade no sentido de buscar soluções para os problemas sociais, inclusive nesse sentido de profissionalizar as ONGs, de exigir que elas funcionem de outra maneira, e também se tornem

\section{Principais artigos}

Sustentabilidade: 0 desafio das políticas sociais no século XXI. Revista da Fundação Seade, São Paulo, 2004.

Mudança sociocultural e participação política nos anos 80. In: SO LA, L.; PAULANI, L. M. Lições da década de 80. São Paulo: Edusp / Genebra: Unrisd, p. 193-200, 1995.

La télévision et les jeunes au Brésil. Revue Internationale des Sciences Sociales, v. 141, p. 531538, sep., 1994.

\section{Trabalhos sobre a participação popular na década de 1980}

Políticas sociais: a relação entre as agências públicas e seus usuários. Coordenadora, Centro Brasileiro de Análise e Planejamento (Cebrap), São Paulo, 1989.

M ovimentos sociais: a busca de novos horizontes interpretativos - 2a. fase. Coordenadora, Centro Bramais eficientes. sileiro de Análise e Planejamento (Cebrap), São Paulo, 1988-89.

Políticas de promoção da participação popular: implantação dos Conselhos de Comunidade nos Centros de Saúde. Coordenadora, Centro Brasileiro de Análise e Planejamento (Cebrap), São Paulo I Instituto de Saúde, Universidade de São Paulo, 1989.

M ovimentos sociais: a busca de novos horizontes interpretativos - 1a. fase. Coordenadora, Centro Brasileiro de Análise e Planejamento (CEBRAP), São Paulo, 1987.

Movimentos sociais na América Latina. Revista Brasileira de Ciências Sociais, São Paulo: Anpocs/ Cortez Editora, v. 1, n. 3, p. 27-37, 1987.

Descentralização administrativa e política local de saúde. Coordenadora, Centro Brasileiro de Análise e Planejamento (Cebrap), São Paulo / Financiadora de Estudos e Projetos (Finep), São Paulo, 1987.

Descentralização administrativa e política local. Coordenadora, Centro Brasileiro de Análise ePlanejamento (Cebrap), São Paulo / Fundação do Desenvolvimento Administrativo (Fundap), São Paulo, 1986.

Formas de participação popular no Brasil contemporâneo. São Paulo em Perspectiva - Revista da Fundação SEADE, São Paulo, v. 1, n. 3, p. 4650, 1985

A periferia de São Paulo e o contexto da ação política. Coordenadora e pesquisadora, Centro Brasileiro de Análise e Planejamento (Cebrap), São Paulo / Universidade de São Paulo, 1983.

\section{NOTAS}

10 Programa Comunidade Solidária foi criado em 1995, no governo Fernando Henrique Cardoso, e presidido por Ruth Cardoso. Seus objetivos eram criar mecanismos de políticas sociais públicas mais eficientes e promover o crescimento da participação da sociedade civil em iniciativas sociais.

\footnotetext{
${ }^{2}$ Depois do Al-3, as primeiras eleições diretas para os governos estaduais ocorreram, ainda sob o regime militar, em 1982. Nas eleições para governadores, as oposições, somadas, obtiveram 25 milhões de votos. O PMDB elegeu nove governadores e o PDT, um.
} 
${ }^{3}$ Assembléia Nacional Constituinte, constituída em 1987 pelos deputados federais e senadores eleitos em 1986, e pelos senadores eleitos em 1982.

${ }^{4}$ Programa Capacitação Solidária.

${ }^{5}$ A Reforma do Marco Legal do Terceiro Setor
passou a ser articulada pelo Comunidade Solidá-
ria em 1995. Desse processo resultaram duas leis:
a Lei no 9.608, que regula o serviço voluntário, e
a Lei no 9.790/99 (conhecida como Lei do Ter-
ceiro Setor), que cria a qualificação de Organiza-
ção da Sociedade Civil de Interesse Público e os
Termos de Parceria entre essas organizações e o Estado.

${ }^{6}$ James Petras, sociólogo americano que é crítico de longa data da atuação das O N Gs.

\footnotetext{
${ }^{7}$ Antonio Gramsci é considerado extremamente importante na introdução de novas dimensões ao marxismo. Diferentemente de Marx, Gramsci acreditava que a sociedade civil não era governada puramente por "relacionamentos materiais" ou econômicos, mas também por "hegemonia". 0 poder dos grupos dominantes está incrustado em leis, regras, normas, hábitos e mesmo em con-
}

senso geral, assumindo dessa forma aquilo que Gramsci chamou de "hegemonia". A hegemonia pode ser entendida como o controle ideológico da sociedade por uma classe, uma fração de classe ou uma aliança de classes. A ideologia da classe dominante corresponde à sua função histórica e aos seus interesses. Dessa maneira, dominações de classe, formas de segregacionismo e mesmo controle do conhecimento científico são formas características desse tipo de hegemonia. Essa hegemonia é sentida pela sociedade política (o Estado) ou pela sociedade civil, que inclui os partidos políticos, os sindicatos, as associações civis.

${ }^{8} \mathrm{~A}$ entrevistadora Ana Cristina Braga Martes foi sua assistente de pesquisa.

\section{Artigo convidado. Aprovado em 10.01.2006.}

\section{Ana Cristina Braga Martes}

Professora da FGV-EAESP. Doutora em Ciência Política pela USP.

Interesses de pesquisa nas áreas de sociologia econômica, migrações internacionais, empreendedorismo, sociologia das organizações.

E-mail: acbmartes@fgvsp.br

Endereço: Rua Itapeva, 474, $7^{\circ}$ andar, Bela Vista, São Paulo - SP, 01332-000.

\section{Mario Aquino Alves}

Professor da FGV-EAESP. Doutor em Administração de Empresas pela FGV-EAESP. Interesses de pesquisa nas áreas de estudos críticos em administração, teoria das organizações e organizações da sociedade civil.

E-mail: maalves@fgvsp.br

Endereço: Rua Itapeva, 474, $11^{\circ}$ andar, Bela Vista, São Paulo - SP, 01332-000. 